\title{
REATORES ANAERÓBIOS OPERADOS EM BATELADA SEQUENCIAL, SEGUIDOS DE LAGOAS DE POLIMENTO, PARA O TRATAMENTO DE ÁGUAS RESIDUÁRIAS DE SUINOCULTURA. PARTE I: PRODUÇÃO DE METANO E REMOÇÃO DE DQO E DE SÓLIDOS SUSPENSOS ${ }^{1}$
}

\author{
ROSE M. DUDA ${ }^{2}$, ROBERTO A. DE OLIVEIRA ${ }^{3}$
}

\begin{abstract}
RESUMO: Neste trabalho, avaliou-se o desempenho de dois reatores anaeróbios operados em batelada sequencial (ASBR), instalados em série, em escala-piloto (R1 e R2 com volumes de $280 \mathrm{~L}$ e $140 \mathrm{~L}$, respectivamente), no tratamento de águas residuárias de suinocultura com concentrações de sólidos suspensos totais (SST) em torno de $10.000 \mathrm{mg} \mathrm{L}^{-1}$. Para o pós-tratamento do efluente do sistema de tratamento com os reatores anaeróbios, utilizaram-se duas lagoas de polimento (L1 e L2 com volume de $1.000 \mathrm{~L}$, cada) em série. As cargas orgânicas volumétricas (COV) aplicadas no primeiro ASBR variaram de 4,43 a 12,75 $\mathrm{g} \mathrm{DQO}_{\text {total }}(\mathrm{L} \mathrm{d})^{-1}$. As eficiências médias de remoção da demanda química de oxigênio total $\left(\mathrm{DQO}_{\text {total }}\right)$ e de SST variaram de 52 a $86 \%$ e de 54 a $87 \%$, respectivamente, no sistema de tratamento anaeróbio composto pelos ASBR. As produções volumétricas médias de metano no sistema de tratamento anaeróbio variaram de 0,628 a $0,786 \mathrm{~m}^{3}$ $\left(\mathrm{m}^{3} \text { reator } \mathrm{d}\right)^{-1}$. A utilização das lagoas de polimento em série permitiu manter eficiências médias de remoção no sistema de tratamento $(\mathrm{R} 1+\mathrm{R} 2+\mathrm{L} 1+\mathrm{L} 2)$ acima de $89 \%$ e $91 \%$ para a $\mathrm{DQO}_{\text {total }} \mathrm{e}$ SST, respectivamente.
\end{abstract}

PALAVRAS-CHAVE: digestão anaeróbia, carga orgânica volumétrica, dois estágios, póstratamento.

\section{PERFORMANCE OF ANAEROBIC SEQUENCING BATCH REACTORS FOLLOWED BY POLISHING PONDS ON THE TREATMENT OF SWINE WASTEWATER. PART I: METHANE PRODUCTION AND COD AND TOTAL SUSPENDED SOLIDS REMOVAL}

\begin{abstract}
On this study the performance of two anaerobic sequencing batch reactors (ASBR) installed in series was evaluated on a pilot-scale testing (volumes of $280 \mathrm{~L}$ and $140 \mathrm{~L}$, respectively) for the treatment of swine wastewater with total suspended solids concentrations (TSS) around $10.000 \mathrm{mg} \mathrm{L}^{-1}$. For the post-treatment of the effluents from the anaerobic treatment system with ASBR, two polishing ponds were used $(1.000 \mathrm{~L}$ of volume each) in series. The organic loading rates (OLR) applied on the first ASBR varied from 4.43 to $12.75 \mathrm{~g}$ total $\mathrm{COD}(\mathrm{L} \mathrm{d})^{-1}$. The mean removal efficiencies for ${ }_{\text {total }}$ COD and TSS varied form 52 to $86 \%$ and from 54 to $87 \%$, respectively, on the anaerobic treating system. The volumetric methane productions on the anaerobic treating system varied from 0.628 to $0.786 \mathrm{~m}^{3}\left(\mathrm{~m}^{3} \text { reactor } \mathrm{d}\right)^{-1}$. The use of polishing ponds in series has allowed the maintenance of mean removal efficiencies above $89 \%$ and $91 \%$ for ${ }_{\text {total }}$ COD and TSS, respectively.
\end{abstract}

KEYWORDS: anaerobic digestion, organic loading rate, two stages, post-treatment.

\footnotetext{
${ }^{1}$ Extraído da dissertação de Mestrado do primeiro autor. Trabalho financiado pela FAPESP.

${ }^{2}$ Eng $^{\mathrm{a}}$ Química, Doutoranda em Microbiologia Agropecuária, Universidade Estadual Paulista, UNESP, Jaboticabal - SP, Fone: (0XX16) 3209-2638, roseduda@fcav.unesp.br.

${ }^{3}$ Engo Agrônomo e Tecnólogo em Construção Civil, Mestre em Agronomia - Produção Vegetal, Doutor em Engenharia Civil Hidráulica e Saneamento, Prof. Doutor, Departamento de Engenharia Rural, UNESP, Jaboticabal - SP, Fone: (0XX16) 3209-2638, raoder@fcav.unesp.br

Recebido pelo Conselho Editorial em: 5-6-2007

Aprovado pelo Conselho Editorial em: 18-2-2009
} 


\section{INTRODUÇÃO}

Os sistemas de tratamento de águas residuárias provenientes de suinoculturas são de grande importância sanitária e ambiental, em virtude do rápido aumento da atividade de produção de suínos, particularmente em pequenas áreas de produção, concentrando grandes quantidades de esterco com alto poder poluente (COSTA \& MEDRI, 2002).

Segundo a Pesquisa Agropecuária Municipal (IBGE, 2007), o plantel brasileiro de suínos é estimado em 35 milhões de cabeças, e na região Sul estão cerca de 14,5 milhões de cabeças. Em Santa Catarina, estima-se a população de suínos em 5,7 milhões de cabeças, e na região oeste de Santa Catarina estão cerca de 4,5 milhões de cabeças, em apenas $26 \%$ da área total do Estado, equivalente a $25.215 \mathrm{~km}^{2}$ (MIRANDA, 2005).

Um sistema de tratamento utilizando o processo anaeróbio pode ser facilmente integrado dentro do sistema de manejo de águas residuárias, os quais são comumente utilizados em propriedades que produzem animais (NDON \& DAGUE, 1994 e 1997). O tratamento anaeróbio de águas residuárias provenientes da criação intensiva de animais pode trazer vários benefícios para o sistema de produção, como geração de energia, estabilização das águas residuárias e controle de odores. O desafio está na redução de custos e na facilidade de adaptação de sistemas contendo reatores anaeróbios para as aplicações nesse tipo de propriedade (KESHTKAR et al., 2001).

$\mathrm{O}$ reator anaeróbio operado em batelada sequencial (ASBR - Anaerobic Sequencing Batch Reactor), desenvolvido por DAGUE et al. (1992), vem sendo amplamente estudado como alternativa aos sistemas contínuos, com algumas vantagens, como a eliminação da sedimentação secundária, a boa retenção de biomassa, a operação simples e a flexibilidade (SHIZAS \& BAGLEY, 2002; RODRIGUES et al., 2003). A retenção de biomassa granular é um importante aspecto no ASBR, possibilitando altas taxas de remoção de sólidos orgânicos com baixos tempos de detenção hidráulica (NDON \& DAGUE, 1994 e 1997).

Cada ciclo operacional do ASBR inclui quatro etapas distintas, realizadas em uma única unidade: alimentação, reação, sedimentação e descarte, como podem ser verificadas na Figura 1 (NDON \& DAGUE, 1997).
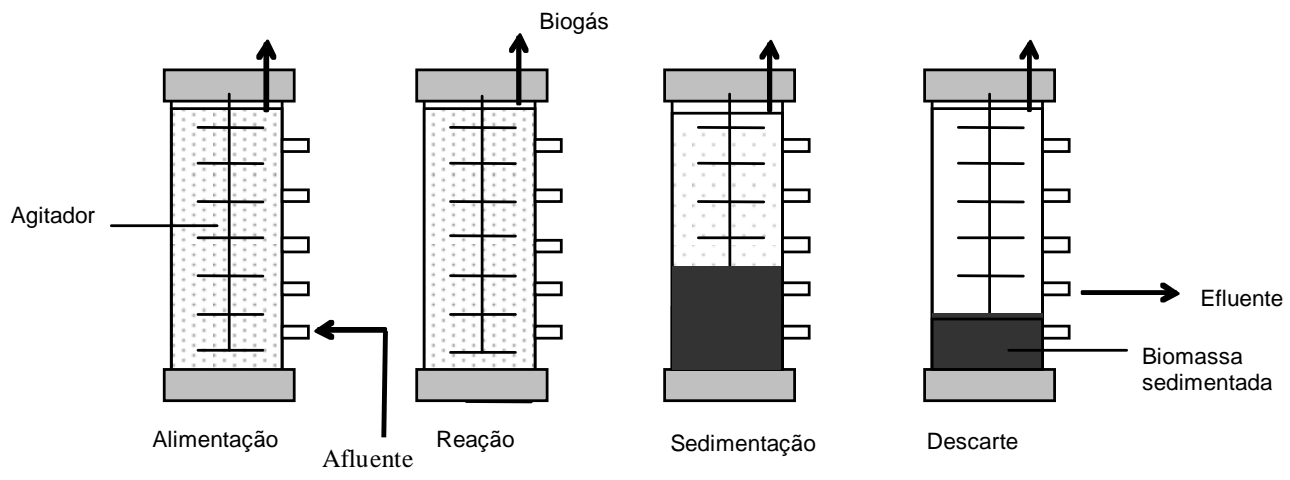

FIGURA 1. Etapas do ciclo operacional do reator anaeróbio operado em batelada sequencial (ASBR). Operating principles of an anaerobic sequencing batch reactor (ASBR).

A utilização de sistemas de tratamento anaeróbio de águas residuárias em dois estágios proporciona o aumento da eficiência da remoção de matéria orgânica. Segundo HAANDEL \& LETTINGA (1994), o processo anaeróbio em dois estágios consiste em dois reatores em série; um para hidrólise parcial da matéria orgânica particulada e outro para digerir compostos solúveis formados no primeiro reator.

Os reatores anaeróbios, em geral, não produzem efluentes que se enquadrem completamente nos padrões da legislação ambiental brasileira (RAMIREZ et al., 2003; CHERNICHARO, 2006). 
Segundo ANDRADE NETO et al. (2002), a racionalização do uso da água e as restrições cada vez mais severas quanto à qualidade de efluentes líquidos, dispostos no meio ambiente, têm exigido a otimização de processos de tratamento de efluentes, sendo quase sempre necessário o póstratamento do efluente de reatores anaeróbios.

Entre as alternativas de pós-tratamento, uma que se destaca é o uso de lagoas de polimento, já que essas mantêm a simplicidade conceitual dos reatores anaeróbios e podem ser utilizadas pelos produtores rurais por constituírem-se em tecnologia relativamente simples (CARMO et al., 2004; MASCARENHAS et al., 2004).

As lagoas de polimento são conceitualmente similares às lagoas de maturação, mas recebem essa nomenclatura específica para distinguir-se de outras lagoas de estabilização, por realizarem o pós-tratamento (polimento) de efluentes de estações de tratamento, em particular dos reatores anaeróbios. Além de ter efetiva remoção de orgânicos patogênicos (objetivo das lagoas de maturação), proporciona-se, ainda, um "polimento" no efluente, em termos de remoção de matéria orgânica (a qual não é o objetivo principal das lagoas de maturação) (CAVALCANTI et al., 2001 e SPERLING, 2005).

Portanto, com este trabalho, pretendeu-se avaliar o desempenho de reatores ASBR em dois estágios, seguidos de lagoas de polimento em série, em escala-piloto, no tratamento de águas residuárias de suinocultura, com concentrações de sólidos suspensos totais em torno de $10.000 \mathrm{mg} \mathrm{L}^{-1}$, variando-se a carga orgânica volumétrica (COV) e o tempo de detenção hidráulica $(\mathrm{TDH})$ quanto à produção de metano e remoções de DQO e sólidos suspensos.

\section{MATERIAL E MÉTODOS}

A unidade experimental (Figura 2) utilizada para o tratamento secundário das águas residuárias de suinocultura foi constituída por uma bomba centrífuga, um depósito de dejetos de suínos (afluente), dois reatores operados em batelada sequencial (ASBR - Anaerobic Sequencing Batch Reactor) em escala-piloto, instalados em série (Figuras 3 e 4). Para a monitorização da produção de biogás, foram instalados gasômetros, conforme descrito por FERNANDES \& OLIVEIRA (2006). O pós-tratamento do efluente dos ASBR foi realizado em lagoas de polimento em série.

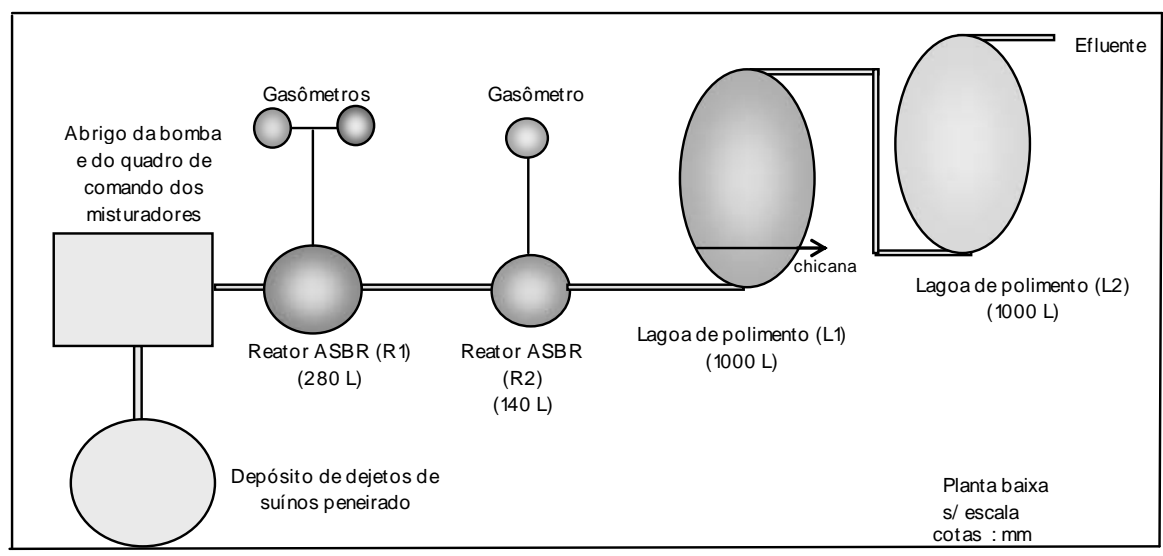

FIGURA 2. Esquema do sistema de tratamento anaeróbio com os reatores ASBR (R1 e R2) e do sistema de pós-tratamento constituído por lagoas de polimento (L1 e L2), em série, em escala-piloto. Scheme of the anaerobic sequencing batch reactor system (R1 and R2) followed by the post-treatment of polishing ponds ( $L 1$ and L2), in series, in a pilot scale.

Os reatores anaeróbios operados em batelada sequencial foram construídos com tubos de PVC, com diâmetros de 500 e $400 \mathrm{~mm}$, com volume total de $280 \mathrm{~L}$ e $140 \mathrm{~L}$, para o primeiro (R1) e 
segundo (R2) reatores, respectivamente (Figuras 3 e 4). O volume reservado para a acumulação de gás na parte superior dos ASBR foi adotado como $14 \%$ do volume total dos reatores $(40 \mathrm{~L}$ e $20 \mathrm{~L}$ para o R1 e R2, respectivamente). Nos ASBR (R1 e R2), foram instalados sistemas de agitação mecânica, compostos por três impelidores, eixo e motorredutor, com acionamento intermitente, controlado por temporizadores.

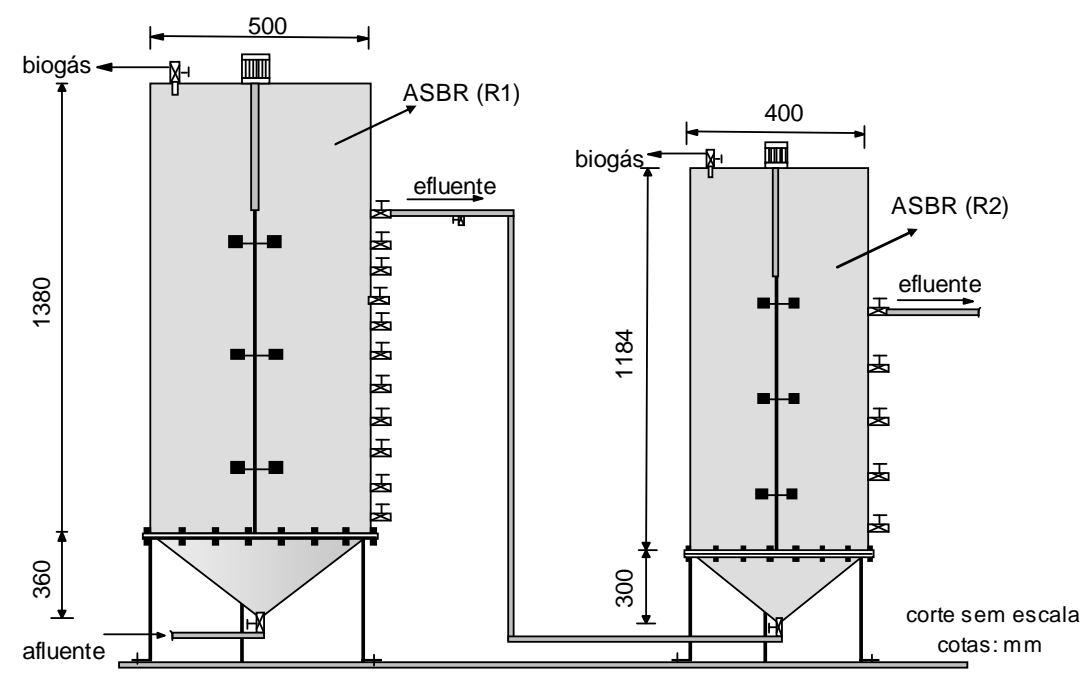

FIGURA 3. Esquema do sistema de tratamento anaeróbio em dois estágios com os reatores ASBR (R1 e R2) em série, em escala-piloto. Cross section scheme of the ASBR in two stages (R1 and R2), in series, in a pilot scale.

Para as lagoas de polimento (L1 e L2), foram utilizadas caixas de polietileno com volume de $1.000 \mathrm{~L}$, profundidade de $0,55 \mathrm{~m}$ e área superficial de $2,25 \mathrm{~m}^{2}$. A primeira lagoa possuia um compartimento na entrada que ocupava $20 \%$ do seu volume total (200 L).

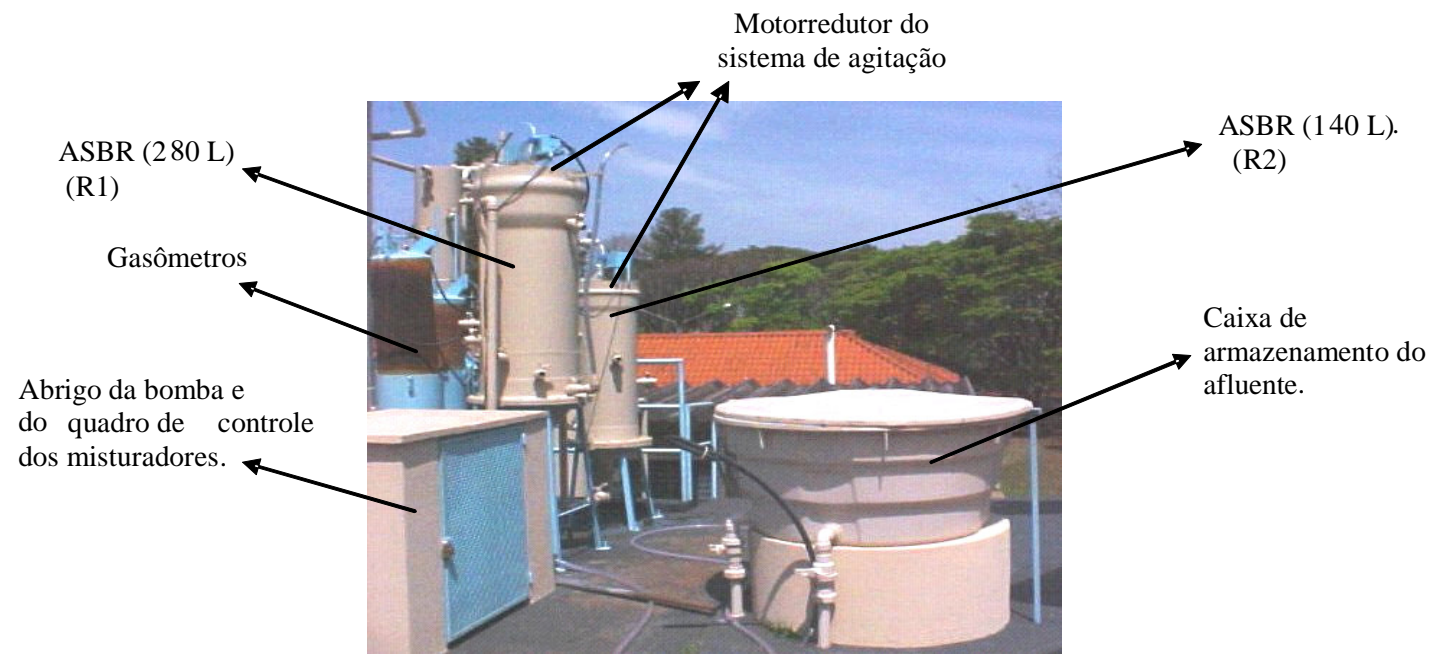

FIGURA 4. Sistema de tratamento anaeróbio composto pelos reatores ASBR em dois estágios (R1 e R2). Anaerobic treatment system composed of ASBR reactors in two stages (R1 and R2).

Os dejetos de suínos utilizados como afluente nos ASBR foram coletados diariamente, em instalações de confinamento de suínos em fase de crescimento e terminação, alimentados com ração 
à base de milho e soja, com complementos vitamínico e mineral. Essas instalações fazem uso intensivo de água (lâmina d'água). Em medições realizadas no verão, verificaram-se vazões média de dejetos de $20 \mathrm{~L}_{\text {animal }}{ }^{-1} \mathrm{~d}^{-1}$, e máxima de $43 \mathrm{~L}_{\text {animal }}{ }^{-1} \mathrm{~d}^{-1}$. Esses valores são próximos aos citados por ZHANG \& DAGUE (1995), de 56,8 $\mathrm{L}$ animal $^{-1} \mathrm{~d}^{-1}$, e os revisados por MONTALVO (1995), que variaram de 6 a $50 \mathrm{~L}_{\text {animal }}{ }^{-1} \mathrm{~d}^{-1}$.

O experimento foi dividido em quatro ensaios, variando-se os volumes de alimentação diário nos ASBR (R1 e R2) e procurando-se manter as concentrações de sólidos suspensos totais no afluente em torno de $10.000 \mathrm{mg} \mathrm{L}^{-1}$.

Nos ensaios 1 e 2, o ciclo operacional do ASBR foi de 24 horas (1 ciclo ao dia), e no terceiro e quarto ensaios de 12 horas ( 2 ciclos ao dia), conforme descritos na Tabela 1.

TABELA 1. Distribuição dos tempos do ciclo operacional e volumes de afluente para cada condição operacional dos reatores anaeróbios operados em batelada sequencial (ASBR). Distribution of the times of the operational cycle and affluent volumes for each operational condition of the anaerobic reactors operated in sequential batch (ASBR).

\begin{tabular}{crrrc}
\hline Características & Ensaio 1 & Ensaio 2 & Ensaio 3 & Ensaio 4 \\
\hline Tempo do ciclo (h) & 24 & 24 & 12 & 12 \\
Volume de alimentação por ciclo (L) & 60 & 80 & 60 & 80 \\
Tempo de alimentação (h) & 0,17 & 0,17 & 0,17 & 0,17 \\
Tempo de reação (h) & 19,00 & 19,00 & 9,00 & 9,00 \\
Tempo de sedimentação (h) & 4,66 & 4,66 & 2,66 & 2,66 \\
Tempo de retirada do sobrenadante (h) & 0,17 & 0,17 & 0,17 & 0,17 \\
\hline
\end{tabular}

Durante a etapa de reação, o sistema de agitação, num gradiente de velocidade $(\mathrm{G})$ em torno de $100 \mathrm{~s}^{-1}$, foi acionado intermitentemente $\left(15\right.$ minutos $\left.^{-1} \mathrm{~h}\right)$, com rotações de 20 a $25 \mathrm{rpm}$, no R1, e de 25 a $35 \mathrm{rpm}$, no R2.

A avaliação de desempenho da unidade experimental baseou-se na monitorização da água residuária de suinocultura bruta do afluente e do efluente tratado, em amostras simples, com frequência de amostragem de duas vezes por semana. Foram determinados o $\mathrm{pH}$, a demanda química de oxigênio total $\left(\mathrm{DQO}_{\text {total }}\right)$, a demanda química de oxigênio dissolvida $\left(\mathrm{DQO}_{\text {diss }}\right)$, a demanda química de oxigênio devido aos sólidos suspensos (DQOss), os sólidos suspensos totais (SST), os sólidos suspensos voláteis (SSV), de acordo com metodologias descritas por APHA/ AWWA/ WPCF (1998); a alcalinidade total (AT) e os ácidos voláteis totais (AVT), conforme metodologias descritas por JENKINS et al. (1983) e DILALLO \& ALBERTSON (1961), respectivamente. $\mathrm{O}$ volume de biogás produzido foi medido diariamente, em gasômetros, como descrito por FERNANDES \& OLIVEIRA (2006), e a composição do biogás foi analisada semanalmente, em cromatografia gasosa, conforme descrito por APHA/ AWWA/ WPCF (1998).

As temperaturas médias do ar foram obtidas na Estação Agroclimatológica do Departamento de Ciências Exatas da UNESP, Jaboticabal-SP.

\section{RESULTADOS E DISCUSSÃO}

Na Tabela 2, estão apresentadas as condições operacionais, a produção volumétrica de metano e as características do afluente e do efluente do sistema de tratamento anaeróbio, em dois estágios, com os reatores ASBR, seguidos de lagoas de polimento, em série, nos ensaios 1; 2; 3 e 4.

As cargas orgânicas volumétricas (COV) aplicadas no primeiro ASBR (R1) variaram de 4,43 a 12,75 g DQO $\mathrm{gotal}(\mathrm{L} \mathrm{d})^{-1}$. Os tempos de detenção hidráulica (TDH) aplicados no sistema de tratamento anaeróbio em dois estágios, seguidos das lagoas de polimento em série, para o pós-tratamento, variaram de 8,1 a 39,2 dias. 
Os valores médios de $\mathrm{DQO}_{\text {total }}$ do afluente foram de $17.726 ; 16.883 ; 19.459$ e $19.119 \mathrm{mg} \mathrm{L}^{-1}$ durante os ensaios 1;2; 3 e 4, respectivamente. As alterações na composição do afluente ocorreram em virtude de variações na idade e no manejo dos animais, das dificuldades operacionais na manutenção da homogeneidade durante o armazenamento e da coleta diária das águas residuárias nas instalações de confinamento de suínos na fase de terminação.

Os valores médios das eficiências de remoção de $\mathrm{DQO}_{\text {total }}$ no $\mathrm{R} 1$ foram de $84 ; 73 ; 56$ e 82\%, e no sistema de tratamento anaeróbio $(\mathrm{R} 1+\mathrm{R} 2)$ foram de 86; 79; 52 e $61 \%$ durante os ensaios 1; 2; 3 e 4 , respectivamente. As eficiências de remoção de $\mathrm{DQO}_{\text {diss }}$ foram de $63 ; 78 ; 46$ e $74 \%$ no R1, e de 73; 77; 59 e 80\% no sistema de tratamento anaeróbio (R1+R2), nos ensaios $1 ; 2 ; 3$ e 4, respectivamente. No $\mathrm{R} 1$, as eficiências de remoção de $\mathrm{DQO}_{\mathrm{ss}}$ foram similares as de $\mathrm{DQO}_{\text {total }}$ (Tabela 3).

As maiores eficiências de remoção de $\mathrm{DQO}_{\text {total }}$ e $\mathrm{DQO}_{\mathrm{ss}}$, utilizando-se do sistema de tratamento anaeróbio (R1+R2), foram observadas no primeiro ensaio, quando houve os maiores tempos de contato entre os microrganismos e o substrato. ZHANG et al. (1997), tratando águas residuárias de suinocultura com SV de 2,7 $\mathrm{g} \mathrm{L}^{-1}$ em ASBR com COV de 1,6 g SV (L d) ${ }^{-1}$, observaram aumento nas eficiências de remoção de $\mathrm{DBO}_{5}$ de $73 \%$ para $86 \%$ com o aumento do TDH de 2 para 3 dias.

Os TDH aplicados na L1 foram de 16,0;12,5; 8,33 e 6,25 dias nos ensaios 1;2; 3 e 4, respectivamente. Os TDH aplicados na L2 foram iguais aos aplicados na L1. No ensaio 4, utilizou-se somente a L1. Como consequência dos valores de TDH e da $\mathrm{DQO}_{\text {total }}$ do afluente das lagoas, as COV foram de 0,$14 ; 0,23 ; 1,14$ e $1,13 \mathrm{~g} \mathrm{DQO}_{\text {total }}(\mathrm{L} \mathrm{d})^{-1}$ na L1, durante os ensaios $1 ; 2 ; 3$ e 4, respectivamente. As eficiências médias de remoção de $\mathrm{DQO}_{\text {total }}$ e de $\mathrm{DQO}_{\text {diss }}$ na $\mathrm{L} 1$ foram de 61; $75 ; 64$ e $73 \%$ e de $34 ; 37 ; 38$ e $20 \%$, nos ensaios $1 ; 2 ; 3$ e 4 , respectivamente (Tabela 3). As cargas orgânicas volumétricas aplicadas na L2 foram de 0,$05 ; 0,06$ e de $0,40 \mathrm{~g} \mathrm{DQO}_{\text {total }}(\mathrm{L} \mathrm{d})^{-1}$ nos ensaios $1 ; 2$ e 3.

Verificou-se importante remoção adicional da $\mathrm{DQO}_{\text {total, }} \mathrm{DQO}_{\text {diss }}$ e $\mathrm{DQO}_{\mathrm{ss}}$, principalmente nos ensaios 2 e 4, nas lagoas de polimento, quando aumentou a participação da $D_{\text {QS }}$ na $D_{\text {Q }} O_{\text {total }}$, fração essa que foi, primeiramente, removida por sedimentação nas lagoas, para, em seguida, ser hidrolisada com acréscimos na DQOdiss. Segundo MAYER et al. (2001), o escoamento no interior das lagoas é horizontal, favorecendo a retenção de sólidos sedimentáveis, mas dificultando o acesso da matéria orgânica solúvel ao lodo ativo particulado depositado no fundo da lagoa. Isso justifica as menores eficiências de remoção de $\mathrm{DQO}_{\text {diss }}$ e maiores de $\mathrm{DQO}_{\mathrm{ss}}$ nas lagoas de polimento.

Os valores médios das concentrações de SST e SSV do afluente foram de 10.700, 10.810, 9.220 e $9.800 \mathrm{mg} \mathrm{L}^{-1}$ e de $7.460 ; 5.330 ; 5.710$ e $4.970 \mathrm{mg} \mathrm{L}^{-1}$ e os valores de SSV corresponderam a 69; 49; 62 e 51\% dos SST, nos ensaios 1; 2; 3 e 4, respectivamente. No efluente do R1, os valores médios de SST e SSV foram de $1.553 ; 1.611 ; 3.954$ e $1.985 \mathrm{mg} \mathrm{L}^{-1}$ e de $1.157 ; 910 ; 2.332$ e $1.157 \mathrm{mg} \mathrm{L}^{-1}$ e os valores de SSV corresponderam a 76; 60; 57 e 55\% dos SST nos ensaios 1; 2; 3 e 4, respectivamente. Houve maior proporção de SSV no efluente, em virtude da retenção de sólidos inorgânicos no lodo dos ASBR, conforme observado por DUDA \& OLIVEIRA (2007).

As eficiências médias de remoção de SST e de SSV no R1 foram de 88; 82; 56 e 81\% e de 88; 81; 57 e 77\%, respectivamente, com TDH de 96; 72; 48 e 36 horas. Os valores médios das eficiências de remoção de SST e SSV aumentaram com o aumento do TDH de 36; 72 e 96 horas, durante os ensaios $1 ; 2$ e 4, respectivamente (Tabela 3 ). 
TABELA 2. Condições operacionais, produção volumétrica de metano e as concentrações médias de DQO $_{\text {total }}$, DQO $_{\text {diss }}$, SST e SSV do afluente e do efluente do sistema de tratamento anaeróbio, em dois estágios, com os reatores ASBR (R1 e R2), seguidos das lagoas de polimento (L1 e L2), em série, nos ensaios 1;2; 3 e 4. Operational conditions, volumetric methane production and the mean values of totalCOD, dissCOD, TSS and VSS of affluent and effluent of the ASBR (R1 and R2) followed by the polishing ponds (L1 and $L 2)$ in series, in the assays $1 ; 2 ; 3$ and 4.

\begin{tabular}{|c|c|c|c|c|c|c|c|c|c|}
\hline \multirow{2}{*}{\multicolumn{2}{|c|}{ Parâmetros }} & \multicolumn{2}{|c|}{ Ensaio 1} & \multicolumn{2}{|c|}{ Ensaio 2} & \multicolumn{2}{|c|}{ Ensaio 3} & \multicolumn{2}{|c|}{ Ensaio 4} \\
\hline & & Média & C.V. & Média & C.V. & Média & C.V. & Média & C.V. \\
\hline Duração do ensai & (dias) & 60 & - & 59 & - & 59 & - & 53 & - \\
\hline Temperatura média & do $\operatorname{ar}\left({ }^{\circ} \mathrm{C}\right)$ & 24 & 7 & 23 & 11 & 18 & 11 & 22 & 11 \\
\hline \multirow{4}{*}{$\mathrm{TDH}(\mathrm{d})$} & $\mathrm{R} 1$ & 4,0 & - & 3,0 & - & 2,0 & - & 1,5 & - \\
\hline & $\mathrm{R} 2$ & 2,0 & - & 1,5 & - & 1,0 & - & 0,7 & - \\
\hline & L1 & 16,6 & - & 12,5 & - & 8,3 & - & 6,2 & - \\
\hline & L2 & 16,6 & - & 12,5 & - & 8,3 & - & $*$ & - \\
\hline \multirow{4}{*}{$\mathrm{COV}\left(\mathrm{g} \mathrm{DQO}_{\text {total }}(\mathrm{L} \mathrm{d})^{-1}\right)$} & $\mathrm{R} 1$ & 4,43 & 26 & 5,62 & 35 & 9,73 & 31 & 12,75 & 30 \\
\hline & $\mathrm{R} 2$ & 1,37 & 42 & 2,41 & 83 & 8,50 & 41 & 4,37 & 28 \\
\hline & L1 & 0,14 & 25 & 0,23 & 75 & 1,14 & 45 & 1,13 & 38 \\
\hline & L2 & 0,05 & 27 & 0,06 & 48 & 0,40 & 59 & $*$ & \\
\hline \multirow{5}{*}{$\mathrm{DQO}_{\text {total }}\left(\mathrm{mg} \mathrm{L}^{-1}\right)$} & Afluente & 17.726 & 26 & 16.883 & 35 & 19.459 & 31 & 19.119 & 30 \\
\hline & Efluente R1 & 2.756 & 42 & 3.705 & 83 & 8.038 & 41 & 4.415 & 28 \\
\hline & Efluente R2 & 2.303 & 25 & 3.199 & 75 & 9.499 & 37 & 7.093 & 63 \\
\hline & Efluente L1 & 894 & 28 & 801 & 32 & 3.383 & 45 & 1.885 & 37 \\
\hline & Efluente L2 & 845 & 27 & 456 & 46 & 1.923 & 59 & $*$ & - \\
\hline \multirow{5}{*}{$\mathrm{DQO}_{\text {dissolvida }}\left(\mathrm{mg} \mathrm{L}^{-1}\right)$} & Afluente & 2.834 & 55 & 2.368 & 31 & 3.517 & 18 & 4.124 & 32 \\
\hline & Efluente R1 & 888 & 22 & 508 & 52 & 1.758 & 40 & 989 & 57 \\
\hline & Efluente R2 & 628 & 44 & 591 & 59 & 1.313 & 45 & 760 & 40 \\
\hline & Efluente L1 & 411 & 33 & 373 & 48 & 813 & 26 & 605 & 54 \\
\hline & Efluente L2 & 266 & 43 & 268 & 61 & 700 & 34 & $*$ & - \\
\hline \multirow{5}{*}{ DQOss $\left(\mathrm{mg} \mathrm{L}^{-1}\right)$} & Afluente & 14.892 & 26 & 14.515 & 38 & 15.943 & 34 & 14.995 & 30 \\
\hline & Efluente R1 & 1.868 & 59 & 3.177 & 98 & 6.652 & 50 & 2.233 & 43 \\
\hline & Efluente R2 & 1.673 & 37 & 2.607 & 90 & 8.186 & 43 & 6.333 & 72 \\
\hline & Efluente L1 & 483 & 48 & 428 & 58 & 2.570 & 60 & 1.280 & 62 \\
\hline & Efluente L2 & 580 & 41 & 188 & 82 & 1.223 & 92 & $*$ & - \\
\hline \multirow{5}{*}{$\operatorname{SST}\left(\mathrm{mg} \mathrm{L}^{-1}\right)$} & Afluente & 10.700 & 32 & 10.810 & 34 & 9.220 & 28 & 9.800 & 19 \\
\hline & Efluente R1 & 1.553 & 63 & 1.611 & 59 & 3.954 & 58 & 1.985 & 82 \\
\hline & Efluente R2 & 1.270 & 43 & 2.240 & 75 & 4.230 & 44 & 3.080 & 62 \\
\hline & Efluente L1 & 470 & 49 & 350 & 24 & 1.500 & 46 & 790 & 69 \\
\hline & Efluente L2 & 560 & 94 & 210 & 48 & 450 & 38 & $*$ & - \\
\hline \multirow{5}{*}{$\operatorname{SSV}\left(\mathrm{mg} \mathrm{L}^{-1}\right)$} & Afluente & 7.460 & 42 & 5.330 & 51 & 5.710 & 35 & 4.970 & 30 \\
\hline & Efluente R1 & 1.157 & 64 & 910 & 47 & 2.332 & 67 & 1.157 & 60 \\
\hline & Efluente R2 & 950 & 50 & 1130 & 72 & 2.420 & 56 & 1.490 & 55 \\
\hline & Efluente L1 & 120 & 89 & 140 & 30 & 500 & 66 & 340 & 99 \\
\hline & Efluente L2 & 140 & 98 & 80 & 62 & 270 & 45 & $*$ & - \\
\hline \multirow{3}{*}{$\begin{array}{c}\text { Produção volumétrica } \\
\text { de } \mathrm{CH}_{4} \\
\left(\mathrm{~m}^{3} \mathrm{CH}_{4}\left(\mathrm{~m}^{3} \text { reator } \mathrm{d}\right)^{-1}\right)\end{array}$} & R1 & 0,558 & 25 & 0,622 & 27 & 0,549 & 44 & 0,518 & 38 \\
\hline & $\mathrm{R} 2$ & 0,144 & 75 & 0,168 & 130 & 0,082 & 110 & 0,148 & 66 \\
\hline & $\mathrm{R} 1+\mathrm{R} 2$ & 0,696 & 24 & 0,786 & 42 & 0,628 & 44 & 0,660 & 42 \\
\hline
\end{tabular}

TDH - tempo de detenção hidráulica; $\mathrm{COV}$ - carga orgânica volumétrica; $\mathrm{DQO}$ total - demanda química de oxigênio total; $\mathrm{DQO}_{\text {diss }}$ - demanda química de oxigênio dissolvida; DQOss - demanda química de oxigênio devido aos sólidos suspensos; SST - sólidos suspensos totais; SSV - sólidos suspensos voláteis; c.v. - coeficiente de variação, * Não se utilizou a lagoa 2. 
TABELA 3. Eficiências médias de remoção de DQO $_{\text {total }}$, DQO ${ }_{\text {diss, }}$ SST e SSV do sistema de tratamento anaeróbio, em dois estágios com os ASBR (R1 e R2) seguidos das lagoas de polimento (L1 e L2) em série, nos ensaios 1; 2; 3 e 4. Removal efficiencies of totalCOD, dissCOD, TSS, VSS for the anaerobic treatment system with reactors ASBR (R1 and R2), followed by polishing ponds (L1 and L2), in series, in the assays $1 ; 2 ; 3$ and 4 .

\begin{tabular}{|c|c|c|c|c|c|c|c|c|c|}
\hline \multirow{2}{*}{\multicolumn{2}{|c|}{$\begin{array}{l}\text { Parâmetros } \\
\text { Eficiência de Remocão (\%) }\end{array}$}} & \multicolumn{2}{|c|}{ Ensaio 1} & \multicolumn{2}{|c|}{ Ensaio 2} & \multicolumn{2}{|c|}{ Ensaio 3} & \multicolumn{2}{|c|}{ Ensaio 4} \\
\hline & & Média & C.V. & Média & C.V. & Média & C.V. & Média & C.V. \\
\hline \multirow{5}{*}{$\mathrm{DQO}_{\text {total }}$} & R1 & 84 & 8 & 73 & 28 & 56 & 13 & 82 & 8 \\
\hline & $\mathrm{R} 1+\mathrm{R} 2$ & 86 & 7 & 79 & 21 & 52 & 38 & 61 & 34 \\
\hline & L1 & 61 & 39 & 75 & 28 & 64 & 60 & 73 & 27 \\
\hline & $\mathrm{L} 1+\mathrm{L} 2$ & 63 & 22 & 86 & 10 & 79 & 35 & $*$ & - \\
\hline & Sistema & 95 & 2 & 97 & 2 & 89 & 29 & 89 & 6 \\
\hline \multirow{5}{*}{$\mathrm{DQO}_{\text {diss }}$} & R1 & 63 & 22 & 78 & 14 & 46 & 72 & 74 & 15 \\
\hline & $\mathrm{R} 1+\mathrm{R} 2$ & 73 & 30 & 77 & 15 & 59 & 43 & 80 & 11 \\
\hline & L1 & 34 & 107 & 37 & 70 & 38 & 50 & 20 & 90 \\
\hline & $\mathrm{L} 1+\mathrm{L} 2$ & 58 & 43 & 54 & 26 & 47 & 38 & $*$ & - \\
\hline & Sistema & 88 & 9 & 88 & 10 & 79 & 24 & 84 & 13 \\
\hline \multirow{5}{*}{$\mathrm{DQO}_{\mathrm{SS}}$} & R1 & 87 & 8 & 70 & 36 & 58 & 16 & 84 & 11 \\
\hline & $\mathrm{R} 1+\mathrm{R} 2$ & 88 & 6 & 79 & 26 & 54 & 33 & 55 & 50 \\
\hline & L1 & 71 & 21 & 83 & 20 & 68 & 30 & 80 & 15 \\
\hline & $\mathrm{L} 1+\mathrm{L} 2$ & 65 & 28 & 93 & 8 & 85 & 17 & * & - \\
\hline & Sistema & 96 & 2 & 99 & 1 & 92 & 8 & 90 & 2 \\
\hline \multirow{5}{*}{ SST } & R1 & 85 & 10 & 82 & 13 & 56 & 38 & 81 & 18 \\
\hline & $\mathrm{R} 1+\mathrm{R} 2$ & 87 & 6 & 76 & 29 & 54 & 44 & 71 & 31 \\
\hline & L1 & 63 & 44 & 84 & 25 & 64 & 51 & 74 & 25 \\
\hline & $\mathrm{L} 1+\mathrm{L} 2$ & 56 & 43 & 91 & 25 & 89 & 59 & $*$ & - \\
\hline & Sistema & 95 & 8 & 98 & 0,8 & 96 & 2 & 91 & 8 \\
\hline \multirow{5}{*}{ SSV } & R1 & 88 & 6 & 81 & 12 & 57 & 47 & 77 & 16 \\
\hline & $\mathrm{R} 1+\mathrm{R} 2$ & 84 & 9 & 79 & 24 & 57 & 45 & 73 & 22 \\
\hline & L1 & 87 & 17 & 88 & 26 & 79 & 118 & 77 & 49 \\
\hline & $\mathrm{L} 1+\mathrm{L} 2$ & 85 & 31 & 93 & 14 & 89 & 18 & $*$ & - \\
\hline & Sistema & 97 & 7 & 97 & 3 & 94 & 5 & 93 & 8 \\
\hline
\end{tabular}

$\overline{\mathrm{DQO}}_{\text {total }}$ - demanda química de oxigênio total; $\mathrm{DQO}_{\text {diss }}$ - demanda química de oxigênio dissolvida; $\overline{\mathrm{DQOss} \text { - demanda }}$ química de oxigênio devido aos sólidos suspensos; SST - sólidos suspensos totais; SSV - sólidos suspensos voláteis; c.v. - coeficiente de variação, * Não se utilizou a lagoa 2.

Com as menores COV ocorreram as maiores remoções de DQO $_{\text {total, }}$ SST e SSV no sistema (R1+R2), nos ensaios 1 e 2. No ensaio 3, foram observadas as menores eficiências de remoção de $\mathrm{DQO}_{\text {total }}, \mathrm{DQO}_{\text {diss }}, \mathrm{SST}$ e SSV, o que se pode atribuir à diminuição da temperatura média diária do ar observada $\left(18^{\circ} \mathrm{C}\right)$.

Segundo NDON \& DAGUE (1994 e 1997) e MASSÉ et al. (2003), o decréscimo na temperatura diminui a atividade dos microrganismos anaeróbios afetando a eficiência do sistema de tratamento. MASSÉ et al. (2003) trabalharam com ASBR (42 L) no tratamento de águas residuárias de suinocultura com DQO total de $48.770 \mathrm{mg} \mathrm{L}^{-1}$ e SV de $12.490 \mathrm{mg} \mathrm{L}^{-1}$, e aplicando COV de $1,2 \mathrm{~g}$ $\mathrm{DQO}_{\text {total }}(\mathrm{L} \mathrm{d})^{-1}$ com temperatura de $20^{\circ} \mathrm{C}$, obtiveram eficiência de remoção de $\mathrm{DQO}_{\text {total }}$ de $89,5 \%$. Com COV de $1,4 \mathrm{~g} \mathrm{DQO}_{\text {total }}(\mathrm{L} \mathrm{d})^{-1}$ e temperatura de $15^{\circ} \mathrm{C}$, a eficiência de remoção de $\mathrm{DQO}_{\text {total }}$ diminuiu para 64\%, evidenciando a influência da diminuição da temperatura e do aumento da COV. As COV aplicadas no R1 foram maiores que as utilizadas por MASSÉ et al. (2003), contudo as eficiências de remoção de $\mathrm{DQO}_{\text {total }}$ foram similares ou superiores em virtude das temperaturas com médias mais altas, de $24 ; 23$ e $22^{\circ} \mathrm{C}$, que ocorreram durante os ensaios $1 ; 2$ e 4 , respectivamente. 
Observa-se, na Figura 5, que no sistema de tratamento anaeróbio com os reatores ASBR (R1 e R2), as eficiências médias de remoção foram acima de $50 \%$ para a $\mathrm{DQO}_{\text {total }}$, $\mathrm{DQO}_{\text {diss }}$, SST e SSV durante os ensaios. As produções volumétricas médias de metano no sistema de tratamento anaeróbio com os ASBR (R1 e R2) variaram de 0,628 a $0,786 \mathrm{~m}^{3} \mathrm{CH}_{4}\left(\mathrm{~m}^{3}\right.$ reator d) ${ }^{-1}$ ) e diminuíram com a menor temperatura no ensaio 3 e a maior COV.

Os valores de $\mathrm{pH}$ do efluente em todos os ensaios foram superiores aos do afluente, indicando a capacidade de tamponamento nos reatores ASBR, em virtude da remoção de ácidos voláteis e ao processo de amonificação. Os valores de $\mathrm{pH}$ do efluente do R1 variaram entre 6,9 e 7,4, e no R2 de 6,9 a 7,6 nos ensaios 1; 2 e 4 (Tabela 4). Segundo CHERNICHARO (2007), a faixa ótima de pH para o desenvolvimento das arqueas metanogênicas é de 6,6 a 7,4, embora possa conseguir-se estabilidade na formação de metano na faixa de 6,0 a 8,0 .

Nos efluentes dos reatores R1 e R2, observaram-se valores de AT maiores que os presentes nos seus afluentes, indicando que houve acréscimo de alcalinidade, proporcionando aumento na capacidade tampão dos reatores. Esses acréscimos de AT foram menores no ensaio 3.

As concentrações médias de AVT no efluente do R1 foram de 108; 99; 208 e $31 \mathrm{mg} \mathrm{L}^{-1}$, e no R2 de 238; 152; 327 e $202 \mathrm{mg} \mathrm{L}^{-1}$, nos ensaios 1; 2; 3 e 4, respectivamente (Tabela 4). Os valores de AVT recomendados por GERARDI (2003) estão na faixa de 50 a $500 \mathrm{mg} \mathrm{L}^{-1}$, para que exista estabilidade no processo anaeróbio.

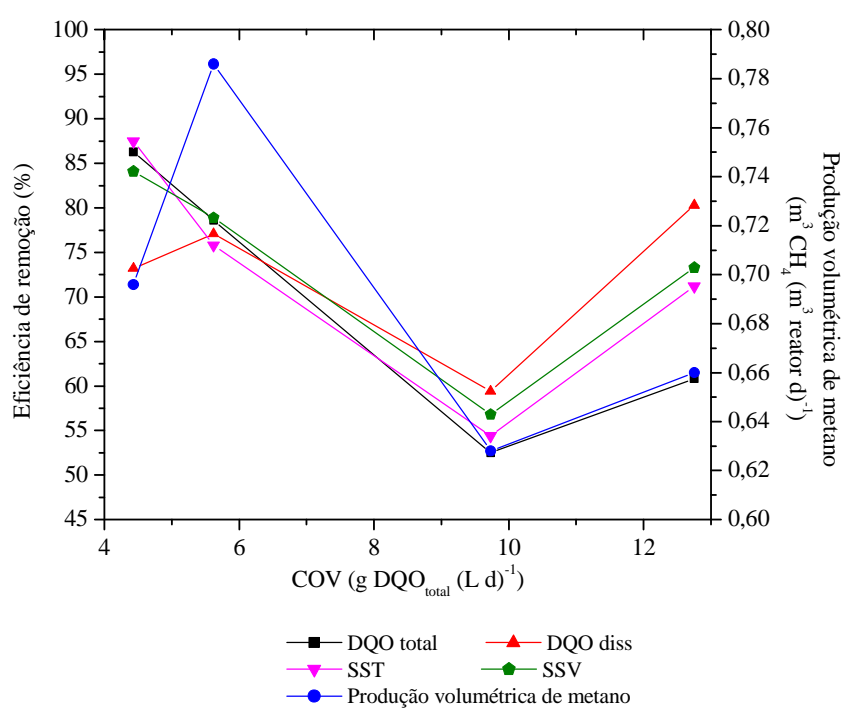

FIGURA 5. Eficiências médias de remoção de $\mathrm{DQO}_{\text {total }}, \mathrm{DQO}_{\text {diss, }}, \mathrm{SST}$, SSV e produção volumétrica de metano no sistema de tratamento anaeróbio em dois estágios com os ASBR (R1 e R2), em função das COV aplicadas no R1. Removal efficiencies of totalCOD, dissCOD, TSS, VSS for the anaerobic treatment system with reactors ASBR (R1 and R2), in function of OLR in R1.

No sistema de tratamento conjunto (ASBR em série + lagoas de polimento em série), verificaram-se eficiências médias de remoção acima de $89 \%$ para $\mathrm{DQO}_{\text {total, }}, 90 \%$ para $\mathrm{DQO}_{\mathrm{ss}}$ e $79 \%$ para $\mathrm{DQO}_{\text {diss, }}$ para as condições operacionais impostas (Tabela 3 e Figura 6).

No sistema de tratamento conjunto (ASBR em série + lagoas de polimento em série), nos ensaios 1 e 2, com TDH de 39,3 e 29,5 dias, as eficiências médias de remoção de DQO $_{\text {total }}$, DQO ${ }_{\text {diss }}$ e $\mathrm{DQO}_{\text {ss }}$ praticamente não apresentaram diferenças e foram estáveis (C.V. em torno de 1,5\%). Embora tenham ocorrido altas remoções de DQO no sistema, as concentrações de $\mathrm{DQO}_{\text {total }}$ no efluente (acima de $456 \mathrm{mg} \mathrm{L}^{-1}$ ) ainda são restritivas ao seu despejo em cursos d'água, considerando-se os padrões de lançamento de efluentes contidos nas legislações ambientais estaduais. 
TABELA 4. Valores médios do $\mathrm{pH}$, alcalinidade total (AT) e ácidos voláteis totais (AVT) no afluente e no efluente do sistema de tratamento em dois estágios com os ASBR (R1 e R2) seguidos de lagoas de polimento (L1 e L2) em série, nos ensaios 1;2; 3 e 4. Average values of pH, total alkalinity (TA), total volatile acids (TVA), in the affluent and effluent of the anaerobic treatment system in two stages with ASBR followed by polishing ponds in series, in the assays $1 ; 2 ; 3$ and 4.

\begin{tabular}{|c|c|c|c|c|c|c|c|c|c|}
\hline \multicolumn{2}{|c|}{ Parâmetros } & \multicolumn{2}{|c|}{ Ensaio 1} & \multicolumn{2}{|c|}{ Ensaio 2} & \multicolumn{2}{|c|}{ Ensaio 3} & \multicolumn{2}{|c|}{ Ensaio 4} \\
\hline & & Média & C.V. & Média & C.V. & Média & C.V. & Média & C.V. \\
\hline \multirow{5}{*}{$\mathrm{pH}$} & Afluente & 5,7 & 5 & 5,8 & 8,0 & 5,9 & 8 & 6,0 & 8 \\
\hline & Efluente R1 & 7,4 & 3 & 7,2 & 2,0 & 6,9 & 7 & 7,4 & 5 \\
\hline & Efluente R2 & 7,6 & 3 & 7,2 & 2,0 & 6,9 & 7 & 7,4 & 5 \\
\hline & Efluente L1 & 7,8 & 2 & 7,8 & 3,0 & 7,2 & 3 & 7,4 & 2 \\
\hline & Efluente L2 & 8,2 & 4 & 8,1 & 0,9 & 7,6 & 2 & * & - \\
\hline \multirow{5}{*}{$\left.\begin{array}{c}\mathrm{AVT} \\
\left(\mathrm{mg} \mathrm{CH}_{3} \mathrm{COOH} \mathrm{L}\right. \\
-1\end{array}\right)$} & Afluente & 1.481 & 42 & 899 & 27 & 1.134 & 21 & 1.363 & 34 \\
\hline & Efluente R1 & 108 & 34 & 99 & 27 & 208 & 22 & 31 & 187 \\
\hline & Efluente R2 & 238 & 35 & 152 & 34 & 327 & 52 & 202 & 48 \\
\hline & Efluente L1 & 347 & 21 & 193 & 23 & 523 & 59 & 220 & 38 \\
\hline & Efluente L2 & 58 & 21 & 57 & 23 & 152 & 18 & $*$ & - \\
\hline \multirow{5}{*}{$\begin{array}{c}\mathrm{AT} \\
\left(\mathrm{mg} \mathrm{CaCO}_{3} \mathrm{~L}^{-1}\right)\end{array}$} & Afluente & 1.358 & 46 & 893 & 18 & 1.626 & 115 & 1.449 & 37 \\
\hline & Efluente R1 & 2.090 & 30 & 1.596 & 14 & 1.670 & 30 & 2.023 & 21 \\
\hline & Efluente R2 & 2.401 & 25 & 1.906 & 22 & 1.918 & 28 & 2.338 & 21 \\
\hline & Efluente L1 & 1.431 & 20 & 1.392 & 14 & 2.271 & 19 & 2.151 & 21 \\
\hline & Efluente L2 & 628 & 20 & 800 & 7 & 2.126 & 10 & $*$ & - \\
\hline
\end{tabular}

c.v. - coeficiente de variação, * Não se utilizou a lagoa 2.

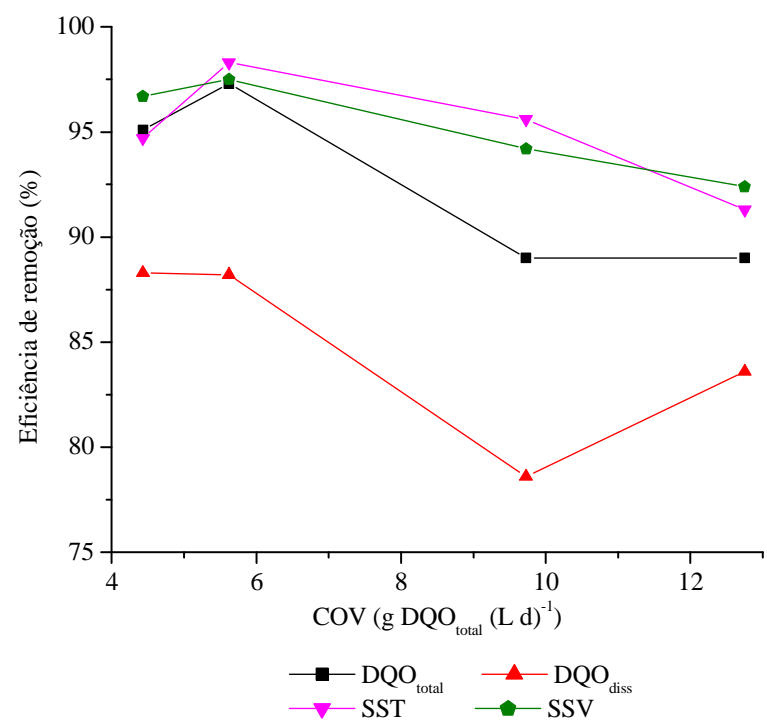

FIGURA 6. Eficiências médias de remoção de DQO $_{\text {total, }}$ DQO ${ }_{\text {diss, }}$ SST, SSV para o sistema de tratamento anaeróbio em dois estágios, com reatores ASBR, seguidos de lagoas de polimento, em função das COV aplicadas no R1. Removal efficiencies of totalCOD, dissCOD, TSS, VSS for the anaerobic treatment system with reactors ASBR, followed by polishing ponds, in function of OLR in R1.

As concentrações de SST e SSV nos efluentes do sistema de tratamento (ASBR em série + lagoas de polimento em série) foram de $560 ; 210$ e $450 \mathrm{mg} \mathrm{L}^{-1}$ e de 140; 80 e $270 \mathrm{mg} \mathrm{L}^{-1}$, nos ensaios 1; 2 e 3, respectivamente. No sistema de tratamento composto pelos ASBR em série, seguidos das lagoas de polimento em série, com TDH de 29,5; 39,3; 19,6 e 8,5 dias, observaram-se 
eficiências de remoção de SST acima de $91 \%$ (com CV de 0,8 a 8,1\%) para concentrações de SST do afluente de $10.700 ; 10.800 ; 9.220$ e $9.800 \mathrm{mg} \mathrm{L}^{-1}$, respectivamente.

COSTA \& MEDRI (2002) avaliaram o desempenho de duas lagoas anaeróbias, uma lagoa facultativa e uma com aguapés em série, com TDH total de 154 dias, no tratamento de águas residuárias de suinocultura decantadas com a $\mathrm{DQO}_{\text {total }}$ e os sólidos totais (ST) em torno de $15.000 \mathrm{e}$ $9.950 \mathrm{mg} \mathrm{L}^{-1}$, respectivamente, e observaram eficiências de remoção de $97 \%$ para $\mathrm{DQO}_{\text {total }}$ e de $86 \%$ para $\mathrm{ST}$.

No sistema de tratamento composto pelos ASBR em série, seguidos das lagoas de polimento

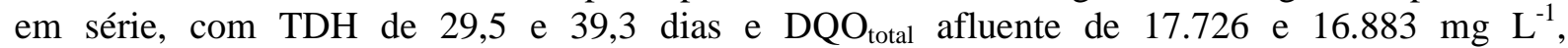
respectivamente, observaram-se eficiências de remoção de $\mathrm{DQO}_{\text {total }}$ e SST acima de $95 \%$. Comparando-se com os resultados obtidos por COSTA \& MEDRI (2002), verifica-se que, com o sistema de tratamento proposto neste estudo, é possível obter eficiências de remoção de $\mathrm{DQO}_{\text {total }} \mathrm{e}$ SST próximas com TDH até cinco vezes menor, evidenciando as vantagens de utilizar reatores anaeróbios (ASBR) e pós-tratamento em lagoas de polimento.

\section{CONCLUSÕES}

O reator anaeróbio operado em batelada sequencial (ASBR) com as eficiências de remoção de DQO e de sólidos suspensos variando de 52 a $88 \%$ e a produção de metano variando de 0,628 a $0,696 \mathrm{~m}^{3} \mathrm{CH}_{4}\left(\mathrm{~m}^{3} \mathrm{~d}\right)^{-1}$, obtido em condições estáveis de operação, com as cargas orgânicas volumétricas aplicadas, pode ser considerado viável para o tratamento de águas residuárias de suinocultura, principalmente em virtude da vantagem da operação intermitente. O desempenho do ASBR foi afetado negativamente pelo decréscimo da temperatura média para valores abaixo de $20^{\circ} \mathrm{C}$.

O pós-tratamento do efluente dos ASBR nas lagoas de polimento em série permitiu manter eficiências médias de remoção estáveis acima de $89 \%$ para DQO $_{\text {total }}$, SST e SSV, com aplicação de TDH acima de 8,5 dias, evidenciando que a associação dos ASBR e das lagoas de polimento em série podem propiciar incrementos na estabilidade e nas remoções de matéria orgânica e de sólidos suspensos no tratamento de águas residuárias de suinocultura.

\section{AGRADECIMENTOS}

À CAPES, à FAPESP e a TIGRE S.A., pelo auxílio financeiro.

\section{REFERÊNCIAS}

APHA/ AWWA/ WPCF. Standard methods for the examination of water and wastewater. $20^{\text {th }}$ ed. Washington, 1998. $1.268 \mathrm{p}$.

ANDRADE NETO, A.C.; HAANDEL, A.; MELO, H.N.S. Van. O uso do filtro anaeróbio para pós-tratamento de efluentes de reatores anaeróbios no Brasil. In. SIMPÓSIO LUSO-BRASILEIRO DE ENGENHARIA SANITÁRIA E AMBIENTAL, 10., 2002, Braga. Anais... Braga:

APESB/APRH/ABES, 2002. 10 p. 2002.

CARMO, F.R.; CAMPOS, C.M.M.; BOTELHO, C.G; COSTA, C.C. Uso de lagoa aerada facultativa como polimento do reator anaeróbio de manta de lodo UASB no tratamento de dejetos de suínos em escala laboratorial. Ciência e Agrotecnologia, Lavras, v.28, n.3, p.600-607, 2004.

CAVALCANTI, P.F.F.; MAYER, M.G.R.; MOREIRA, E.A.; HAANDEL, A. Van. Lagoas de polimento para pós-tratamento de esgotos digeridos - Parte 2: remoção de patógenos. In: CHERNICHARO, C.A.L. (Coord.). Pós-tratamento de efluentes de reatores anaeróbios. Belo Horizonte: FINEP, 2001. p.86-91.

CHERNICHARO, C.A.L. de. Post-treatment options for the anaerobic treatment of domestic wastewater. Reviews in Environmental Science and Bio/Technology, v.5, n.1, p.73-92, 2006. 
CHERNICHARO, C.A.L. de. Reatores anaeróbios: princípios do tratamento biológico de águas residuárias. 2.ed. Belo Horizonte: Departamento de Engenharia Sanitária e Ambiental, Universidade Federal de Minas Gerais, 2007. 379 p.

COSTA, R.H.R. da; MEDRI, W. Modelling and optimisation of stabilisation ponds system for the treatment of swine wastes: organic matter evaluation. Brazilian Archives of Biology and Technology, Curitiba, v.45, n.3, p.385-392, 2002.

DAGUE, R.R.; HABBEN, C.E.; PIDAPARTI, S.R. Initial studies on the anaerobic sequencing batch reactor. Water Science and Technology, Oxford, v.26, n.9-11, p.2.429-2.432, 1992.

DILALLO, R.; ALBERTSON, O.E. Volatile acids by direct titration. Journal Water Pollution Control Federation, Alexandria, v.33, n.4, p.356-365, 1961.

DUDA, R.M.; OLIVEIRA, R.A. de. Caracterização de lodo de reatores sequenciais em batelada anaeróbio, em série, tratando águas residuárias de suinocultura. In: CONGRESSO BRASILEIRO DE ENGENHARIA AGRÍCOLA, 36., 2007, Bonito. Anais... Jaboticabal: Associação Brasileira de Engenharia Agrícola, 2007. 1 CD- ROM.

FERNANDES, G.F.R.; OLIVEIRA, R.A. Desempenho de processo anaeróbio em dois estágios (reator compartimentado seguido de reator UASB) para tratamento de águas residuárias de suinocultura. Engenharia Agrícola, Jaboticabal, v.26, n.1, p.243-256, 2006.

GERARDI, M.H. The microbiology of anaerobic digesters. New Jersey: Wiley \& Sons, 2003. $130 \mathrm{p}$.

HAANDEL, A.C. Van.; LETTINGA, G. Anaerobic sewage treatment: a practical guide for regions with a hot climate. Chichester: John Wiley, 1994. 226 p.

IBGE. FUNDAÇÃO INSTITUTO BRASILEIRO DE GEOGRAFIA E ESTATÍSTICA. Disponível em: <http://sidra.ibge.gov.br>. Acesso em: 15 mar. 2008.

JENKINS, S.R.; MORGAN, J.M.; SAWYER, C.L. Measuring anaerobic sludge digestion and growth by a simple alkalimetric titration. Journal Water Pollution Control Federation, Alexandria, v.55, n.5, p.448-453, 1983.

KESHTKAR, A.; GHAFORIAN, H.; ABOLHAMD, G.; MEYSSAMI, B. Dynamic simulation of cyclic batch anaerobic digestion of cattle manure. Bioresource Technology, Barking, n.80, p.9-17, 2001.

MASCARENHAS, L.C.; SPERLING, M.; CHERNICHARO, C.A.L. de. Avaliação de lagoas de polimento rasas, em série, para o pós-tratamento de efluentes de reator UASB. Engenharia Sanitária e Ambiental, Rio de Janeiro, v.9, n.1, p.45-54, 2004.

MASSÉ, I.; MASSÉ, L.; CROTEAU, F. The effect of temperature fluctuations on psychrophilic anaerobic sequencing batch reactors treating swine manure. Bioresource Technology, Barking, v.38, n.1, p.57-62, 2003.

MAYER, M.G.R.; MOREIRA, E.A.; FRASSINETTI, P.; CAVALCANTI, P.F.F.; HAANDEL, A. Van. Lagoas de polimento para pós-tratamento de esgotos digerido - Parte 1: Remoção de matéria orgânica e sólidos em suspensão In: CHERNICHARO C.A.L. (Coord.) Pós-tratamento de efluentes de reatores anaeróbios: coletânea de trabalhos técnicos. Belo Horizonte/ FINEP, 2001. v.2, p.5968.

MIRANDA, C.R. de. Ordenamento sustentável da suinocultura em Santa Catarina. Suinocultura Industrial, São Paulo, n.7, p.14-19, 2005.

MONTALVO, S. Industrial and rural piggeries wastewaters. In : INTERNACIONAL COURSE: TREATMENT OF AGRO-INDUSTRIAL RESIDUES. CASE STUDIES OF WASTEWATER TREATMENT, Ciudad de México, 1995. Proceedings... Cuidad de México: Universidad Nacional Autónoma de México, 1995. p.102-117. 
NDON, U.J.; DAGUE, R.R. Low temperature treatment of dilute wastewaters using the anaerobic sequencing batch reactor. In: INDUSTRIAL WASTE CONFERENCE, 49., 1994, Purdue.

Proceedings... Chelsea: Ann Arbor Press, 1994. p.563-580.

NDON, U.J.; DAGUE, R.R. Effects of temperature and hydraulic retention time on anaerobic sequencing batch reactor treatment of low-strength wastewater. Water Research, Oxford, v.31, n.10, p.2.455-2.466, 1997.

RAMIREZ, O.P.; QUADRO, M.S.; ANTUNES, R.M.; KOETZ, P.R. Influência da carga orgânica volumétrica aplicada no pós-tratamento de águas residuárias de suinocultura por contactores biológicos rotatórios e reator anóxico. Revista Brasileira de Agrociência, Pelotas, v.9, n.4, p.413420, 2003.

RODRIGUES, J.A.D.; RATUSZNEI S.M.; CAMARGO, E.F.M.; ZAIAT, M. Influence of agitation rate on the performance of an anaerobic sequencing batch reactor containing granulated biomass treating low-strength wastewater. Advances in Environmental Research, London, v.7, n.3, p.405410, 2003.

SHIZAS, I.; BAGLEY, D.M. Improving anaerobic sequencing reactor performance by modifying operational parameters. Water Research, Oxford, v.36, p.363-367, 2002.

SPERLING, M. Van. Introdução à qualidade das águas e ao tratamento de esgotos. 3.ed. Belo Horizonte: Departamento de Engenharia Sanitária e Ambiental, Universidade Federal de Minas Gerais, 2005. 452 p.

ZHANG, R.H.; DAGUE, R.R. Treatment of swine wastes by the anaerobic sequencing batch reactors system. In. INTERNATIONAL SYMPOSIUM ON AGRICULTURAL AND FOOD PROCESSING WASTES, 7, 1995, Chicago. Proceedings... Chicago: ASAE, 1995. p.301-308.

ZHANG, R.H.; YIN, Y.; SUNG, S.; DAGUE, R.R. Anaerobic treatment of swine waste by the anaerobic sequencing batch reactor. Transactions of the ASAE, St. Joseph, v.43, n.6, p.761-767, 1997. 